\title{
A closely linked DNA marker for facioscapulohumeral disease on chromosome $4 \mathrm{q}$
}

\author{
M Upadhyaya, P W Lunt, M Sarfarazi, W Broadhead, J Daniels, M Owen, P S Harper
}

\begin{abstract}
Close linkage of a hypervariable DNA probe on chromosome 4q (pH30, locus D4S139) has been found with the locus for facioscapulohumeral disease. Three recombinants were identified in a total of 140 meioses, giving a maximum lod score of 36.77 at a recombination fraction of 0.02 . All but two of the families studied proved informative with this probe; all informative families showed evidence of linkage (except one family with a single scorable meiosis), making genetic heterogeneity unlikely from our data. The close linkage and highly informative nature of the probe will make it suitable for clinical application in presymptomatic and prenatal diagnosis. We have also confirmed loose linkage with the marker (Mfd22, locus D4S171) used to establish the initial assignment of the disorder to chromosome 4.
\end{abstract}

Facioscapulohumeral disease (FSHD) is one of the commonest of the muscular dystrophies, with a prevalence estimated at around 5 per $100000 .^{1-3}$ It follows autosomal dominant inheritance and is extremely variable both in severity and age of symptomatic onset. Although in most cases weakness first affects the facial muscles in childhood, symptomatic presentation, usually with shoulder girdle weakness,

Institute of Medical Genetics, University of Wales College of Medicine, Heath Park, Cardiff CF4 4XN. $M$ Upadhyaya, P W Lunt, W Broadhead, J Daniels, $M$ Owen, P S Harper

Clinical Genetics Unit, Bristol Children's Hospital, Bristol.

P W Lunt

Department of Pediatrics, University of Connecticut Health Center, Farmington, CT, USA. M Sarfarazi

Department of Psychological Medicine, University of Wales College of Medicine, Cardifi CF4 4XN. M Owen

Correspondence to Dr Upadhyaya.

Received for publication 19 January 1991.

Revised version accepted for publication 9 April 1991. is often delayed until the second or third decades or even later. ${ }^{4}$ The condition is progressive, and although between 10 to $20 \%$ of those affected become severely disabled by middle age, ${ }^{3}$ others have minimal symptoms throughout life. ${ }^{25}$ No reliable presymptomatic test for the disorder has been available.

The variability of expression, and the need for accurate presymptomatic detection particularly for genetic counselling, have given impetus to a search for the gene responsible for FSHD. A collaborative group including ourselves has reported exclusion data on a considerable proportion of the genome. ${ }^{67}$ Although clinical studies of large families favour a single FSHD gene locus, ${ }^{3}$ the possibility of genetic heterogeneity has remained, including a possible form of spinal muscular atrophy phenotypically indistinguishable from FSHD. ${ }^{8}$ Recently, linkage to a DNA marker on chromosome 4 has been reported in nine Dutch kindreds'; while these results found no evidence for genetic heterogeneity, the linkage was insufficiently close (13\% recombination) to permit clinical application.

Based on our independent linkage panel of 24 families with FSHD from Great Britain, ${ }^{7}$ we report here extremely close linkage of $F S H D$ to a new DNA marker on the long arm of chromosome 4, which should allow application in presymptomatic detection and prenatal diagnosis. We also confirm loose linkage with the marker originally reported. Preliminary data from this study have already been presented in brief. ${ }^{10}$

Materials and methods

Our family database, which has been reported earlier, ${ }^{7}$ comprises 24 families with 151 affected and 248 unaffected subjects, making 194 potentially informative meioses, 34 of which are phase known (figure). A total of 389 out of 399 subjects were assessed clinically by one of us (PL) in their own homes. For inclusion in the linkage panel at least one member from each kindred was required to have facial weakness and to have been diagnosed previously as having facioscapulohumeral muscular dystrophy with supportive electromyogram or muscle histopathology or both. Several of the kindreds had been reported previously by other authors ${ }^{811-13}$ including one (family 067) in which some subjects 


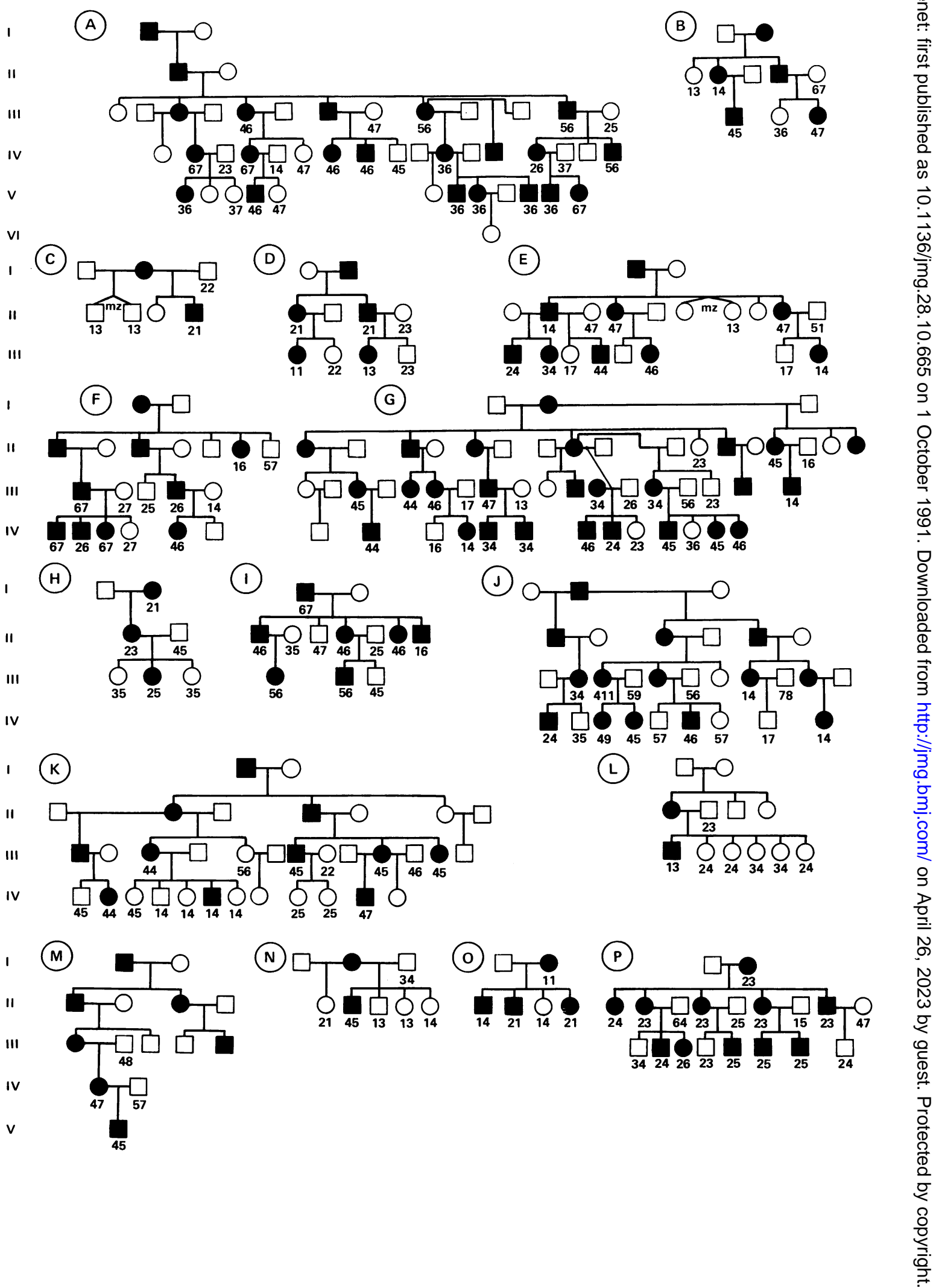



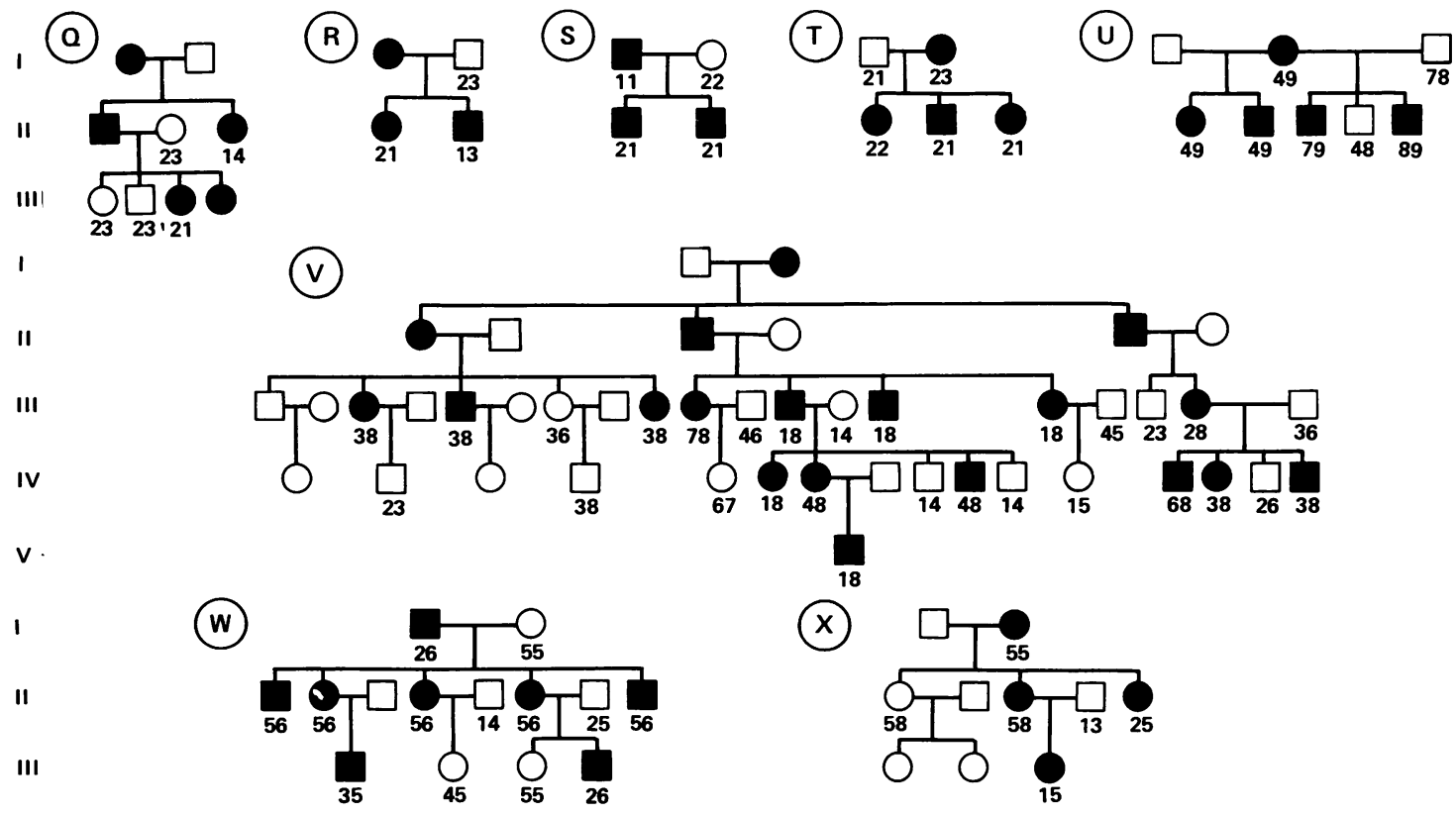

Family pedigrees with genotype data for pH30. Family numbers are as follows: $A$ 001, B 002, C 003, D 004, E 005, $F$ 006, G 009, H 011, I 012, F 025, K 026, L 027, M 028, N 029, O 034, P 035, Q 039, R 041, S 042, T 056, U 062, $V 067, W 087, X 091$.

had been diagnosed independently as having FSH type spinal muscular atrophy. Fourteen of 60 subjects with minimal clinical signs of disputable significance were included in the linkage analysis with status scored from empirical criteria for combinations of 'hard' and 'soft' signs based on graded weakness in appropriate muscle groups and raised serum creatine kinase levels, as detailed previously. ${ }^{14}$ Excluded from analysis were any apparently unaffected subjects under 15 years of age, at which age the penetrance of the FSHD gene is estimated as $70 \%$ or less, and 46 other remaining cases of clinical doubt. Subjects from families reported previously $^{811-13}$ were included in the linkage analysis only after clinical reassessment, but in some cases this allowed updating and extension of the original pedigrees. There were 10 subjects from three families (families 005, 006, and 067) in whom after reassessment we were unable to confirm the previously reported 'affected' status. ${ }^{812}$ Two of these cases (from family 005) have consistently been included as 'unaffected' in our linkage analysis; the remaining eight cases in whom clinical status remained in doubt, and four others previously reported as 'unaffected' (from families 006 and 067) were consistently excluded.

DNA microsatellite markers Mfd22 (D4S171), ${ }^{15}$ which maps to chromosome 4, and pH30 (D4S139), ${ }^{16}$ which has been localised to the distal long arm by multipoint mapping, were used in this analysis. DNA was extracted, digested with appropriate enzymes, fractionated on $0.8 \%$ agarose gel by conventional electrophoresis, and Southern blotted onto Hybond $\mathrm{N}$ (Amersham). The membranes were hybridised overnight with the DNA probe labelled with ${ }^{32} \mathrm{P}$ by the random hexanucleotide primed method. ${ }^{17}$ The posthybridisation wash was in $2 \times$ SSC, $0.1 \%$ SDS and the stringency of washing was increased as necessary. Standard polymerase chain reactions were carried out in a total volume of $25 \mu \mathrm{l}$. This contained $20 \mathrm{ng}$ of genomic DNA template, $25 \mathrm{pmol}$ of each oligodeoxynucleotide primer, $200 \mu \mathrm{mol} / 1$ each of dTTP, dGTP, and dCTP, $25 \mu \mathrm{mol} / 1 \mathrm{dATP}, 10 \mu \mathrm{Ci}$ ${ }^{35} \mathrm{~S}$ dATP at $500 \mathrm{Ci} / \mathrm{mmol}, 50 \mathrm{mmol} / 1 \mathrm{KCl}, 10 \mathrm{mmol} / 1$ Tris (pH 8.3), $1.5 \mathrm{mmol} / 1 \mathrm{MgCl}, 0.01 \%$ gelatin, and 1 unit of Taq polymerase (Perkin Elmer Cetus). The reaction mixes were overlaid with mineral oil. After an initial denaturation period of five minutes at $94^{\circ} \mathrm{C}$ they were processed through 25 temperature cycles consisting of 20 seconds at $54^{\circ} \mathrm{C}$ (annealing), 30 seconds at $72^{\circ} \mathrm{C}$ (elongation), and 20 seconds at $94^{\circ} \mathrm{C}$ (denaturation). The last elongation step was lengthened to 10 minutes. Then $10 \mu \mathrm{l}$ of the amplified DNA were mixed with $4 \mu$ l of formamide loading buffer and loaded onto a denaturing polyacrylamide $(6 \%)$ sequencing gel. Gels were run for three to four hours at 50 to $60 \mathrm{~W}$. They were then fixed and dried before autoradiography. Dideoxy sequencing ladders of $\mathrm{M} 13 \mathrm{mp} 18$ were used as size standards.

Two point analysis to determine the maximum likelihood recombination distance and equivalent lod score $(\mathrm{Z})$ between the disease locus FSHD and 
the DNA probe loci was performed using MLINK from version 5.03 of the LINKAGE package. ${ }^{18}$ Confidence intervals (CI) were calculated as all values of $\theta$ for which the lod score was within one unit of the maximum. ${ }^{19}$ Unaffected children under 15 years of age were excluded from analysis; no other allowance was made for possible heterozygous status in older unaffected subjects, for whom the risk is $5 \%$ or less above the age of 20 years. ${ }^{14}$

\section{Results}

Table 1 summarises our data for the two chromosome 4 markers showing linkage with FSHD. Our data with the DNA microsatellite marker Mfd22 (D4S171) support the chromosomal assignment to 4q found by Wijmenga et al, ${ }^{9}$ though our maximum recombination fraction of 0.21 (confidence limits $0 \cdot 10$ to 0.37 ) suggests looser linkage than in their results.

By contrast, the data for probe $\mathrm{pH} 30$ (D4S139) show extremely close linkage, with a peak lod score of 36.77 at a recombination fraction of 0.02 . This hypervariable marker is highly polymorphic, showing 15 identifiable alleles, and with only two families of the 23 studied being uninformative. (DNA samples from one family were contaminated, so this family was excluded from the analysis.)

The data for linkage between the two marker loci given in table 1 show a maximum recombination fraction of 0.16 at a lod score of 3.01 and with wide confidence intervals $(0.08$ to 0.29$)$.

Table 2 gives the data for D4S139 and FSHD separately by family. Only three crossovers were found in a total of 140 scorable meioses; two occurred in families showing evidence of linkage (families 035 and 087) and one was the single scorable meiosis in family 028 , so that our data provide no evidence for genetic heterogeneity. The individual pedigrees are shown in the figure together with genotype data for $\mathrm{pH} 30$.

The recombinant event noted in family 028 was in a 15 year old subject whose affected status was questionable, but was scored as 'affected' by the empirical criteria. The recombinant subject in family 087 was also young (14 years) but was undoubtedly 'affected', albeit mildly. In family 035 the recombinant subject was scored as 'unaffected' at the age of 18 years, and again on reassessment at 22
Table 2 Two point linkage analysis between $\mathrm{pH} 3 \mathrm{O}$ and FSHD for separate families.

\begin{tabular}{|c|c|c|}
\hline Family No & $\theta \max$ & $Z_{\max }$ \\
\hline $\begin{array}{r}1 \\
2 \\
4 \\
5 \\
6 \\
9 \\
11 \\
12 \\
25 \\
26 \\
27 \\
28 \\
29 \\
35 \\
39 \\
41 \\
56 \\
62 \\
67 \\
87 \\
91\end{array}$ & $\begin{array}{l}0.00 \\
0.00 \\
0.00 \\
0.00 \\
0.00 \\
0.00 \\
0.00 \\
0.00 \\
0.00 \\
0.00 \\
0.00 \\
0.49 \\
0.00 \\
0.08 \\
0.00 \\
0.00 \\
0.00 \\
0.00 \\
0.00 \\
0.11 \\
0.00\end{array}$ & $\begin{array}{l}5.28 \\
1.02 \\
1.09 \\
2.8 \\
2.7 \\
5.9 \\
0.90 \\
2.10 \\
2.59 \\
1.76 \\
1.50 \\
-0.009 * \\
1.20 \\
1.78 \\
0.72 \\
0.20 \\
0.60 \\
8.82 \\
5.91 \\
1.04 \\
0.30\end{array}$ \\
\hline
\end{tabular}

*(Family 028 at $\theta=0.02, Z=-1.40)$.

years after the $\mathrm{pH} 30$ typing result. DNA typing with pH30 was informative in 12 of 13 other subjects whose affected status was questionable who were included in the linkage analysis; in all 12 cases the linkage data supported the scoring of status according to the empirical clinical criteria, including one of the subjects (from family 005) scored on reassessment as 'unaffected', but who had appeared in a previous report ${ }^{12}$ as 'affected' both on clinical grounds and because of retinal vascular changes; pH30 was uninformative in the other similar case.

\section{EXCLUSION DATA}

Until June 1990 the chromosomal localisation of FSHD was unknown, though individual and pooled exclusion data had been published. ${ }^{6-820-23}$ Such data remain relevant in determining whether genetic heterogeneity exists, and our additional unpublished data for other chromosomes are summarised in table 3. Of particular note is the positive lod score of 1.56 at a recombination fraction of 0.10 for the oestrogen receptor locus $(E S R)$ on chromosome 6q. Because of the proximity of this to the autosomal dystrophin locus, ${ }^{24}$ the latter appeared to be an important candidate gene for FSHD, but analysis of a polymorphism at this locus (using probe BSM7), in

Table 1 Two point linkage analysis between FSHD and the two DNA marker loci (D4S171 and D4S139).

\begin{tabular}{|c|c|c|c|c|c|}
\hline Probe & Locus & Linkage to & $\theta \max$ & $\mathrm{Z} \max$ & $95 \% \mathrm{CI}$ \\
\hline $\begin{array}{l}\text { Mfd22 } \\
\text { pH30 }\end{array}$ & $\begin{array}{l}D 4 S 171 \\
D 4 S 139 \\
D 4 S 139\end{array}$ & $\begin{array}{l}F S H D \\
F S H D \\
D 4 S 171\end{array}$ & $\begin{array}{l}0.21 \\
0.02 \\
0.16\end{array}$ & $\begin{array}{r}1.98 \\
36.77 \\
3.01\end{array}$ & $\begin{array}{l}0.10-0.37 \\
0-0.05 \\
0.08-0.29\end{array}$ \\
\hline
\end{tabular}


Table 3 Lod scores for linkage between other DNA loci and FSHD.

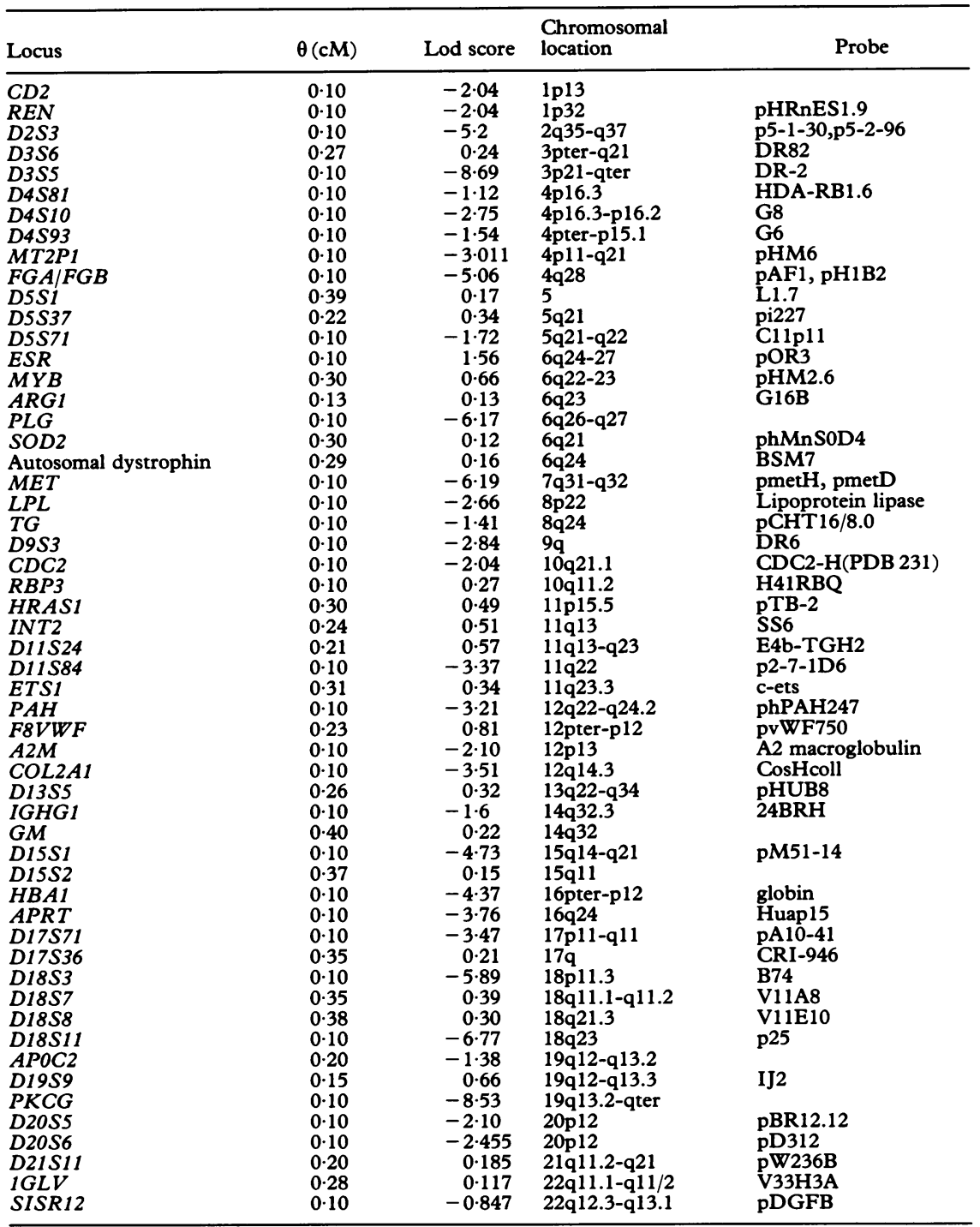

conjunction with Dr Kay Davies, showed frequent recombination. It should also be noted that those families contributing most to the positive score at the oestrogen receptor locus (families 035, 006, and 087) also show positive scores for D4S139, suggesting that chance rather than locus heterogeneity has been responsible for the apparent evidence for linkage at this locus.

\section{Discussion}

Our results not only confirm the assignment of the gene for FSHD to the long arm of chromosome 4, but for the first time provide a tightly linked and highly informative marker locus that is suitable for presymptomatic and prenatal diagnosis. We have already shown that the variability in manifestation and age at onset of FSHD is such as to make molecular genotyping clinically important in confirming or excluding the presence of the gene in subjects at risk, ${ }^{14}$ while the severity in a proportion of affected subjects is such as to make prenatal diagnosis an important option for some family members. ${ }^{3}$

D4S139 is likely to prove a particularly suitable marker for clinical use in view of its highly poly- 
morphic nature, rendering almost all families informative, and the closeness ( $2 \%$ recombination) of the linkage. It is likely that the current confidence limits ( 0 to $5 \%$ ) will be further narrowed in the near future as further data are obtained.

Our data give no support for genetic heterogeneity in FSHD, two of the only three recombinants observed being in families showing clear evidence of linkage to $4 \mathrm{q}$; the third recombinant was the single scorable meiosis in the family and involved a subject whose affected status was questionable. Since our family panel contains 24 kindreds of different severity, including childhood onset, ${ }^{3}$ and also three kindreds, branches of which were diagnosed elsewhere as 'FSH spinal muscular atrophy', ${ }^{38}$ it seems likely that a single genetic locus is responsible for FSHD. Nevertheless, until more data are available we would urge caution in clinical application in families that are too small individually to provide evidence for linkage, and would also recommend that, for the present, families should be analysed as a whole so that the presence of linkage can be confirmed.

Our finding of a closely linked marker will also be helpful in assessing the significance of associated non-muscular features of FSHD. Both nerve deafness $^{25}$ and retinal changes ${ }^{12}$ have been reported in association with the disorder, but it is currently not clear how consistent or universal such abnormalities are, nor whether they can be used in presymptomatic detection in the absence of neuromuscular abnormalities, particularly since we have found one case in which the DNA linkage analysis supports our scoring of 'unaffected' clinical status in preference to a previously reported retinal vascular abnormality. The closeness of the linkage with D4S139 should clarify these points in other cases.

The precise localisation of the FSHD gene on chromosome $4 \mathrm{q}$ is currently under study, as is its relationship to other genetic markers in the region. These markers include the DNA probe EFD139, ${ }^{26}$ the factor XI gene (FII), ${ }^{27}$ and the autosomal breakpoint of the $\mathrm{X} ; 4$ translocation found in a patient with Duchenne muscular dystrophy. ${ }^{28}$ Study of the relationship of FSHD to these and further loci should determine flanking markers for the disorder and should also contribute to our understanding of the detailed map of this region of chromosome 4.

There are currently no obvious candidate genes for FSHD known on the basis of either its chromosomal localisation or the nature of the neuromuscular defect; the autosomal dystrophin locus has been conclusively excluded by the results described above. However, the accurate localisation that now exists for FSHD will make the assessment of future candidate genes feasible and will also allow the techniques of physical mapping to be applied to the characterisation of a well defined and relatively restricted chromosomal region.
Finally, the existence of close and continuing collaboration between the groups involved in research on FSHD, something that has already proved of great value in the initial localisation of the gene, should be of even greater help in subsequent steps towards isolation of the gene itself.

We thank Drs E Milner and J Murray for their kind gift of DNA probes, the numerous clinicians, in particular Dr Robin Fitzsimons and Professor Richard Edwards, who referred families for study, and the families themselves for their cooperation. We thank Iain Fenton for plotting the pedigrees. Dr M Owen is supported by the Wellcome Trust. This work was supported by a grant from the Muscular Dystrophy Group of Great Britain.

1 Becker PE. Dystrophia musculorum progressiva. Eine genetische und klinische Untersuchung der muskeldystrophien. Stuttgart: Georg Thieme Verlag, 1953.

2 Padberg G. Facioscapulohumeral disease. MD thesis, University of Leiden, 1982.

3 Lunt PW, Harper PS. Genetic counselling in facioscapulohumeral muscular dystrophy. $f$ Med Genet 1991;28:655-64.

4 Walton J, Gardner-Medwin D. The muscular dystrophies. In: Walton J, ed. Disorders of voluntary muscle. 5th ed, chap 15. Edinburgh: Churchill Livingstone, 1988.

5 Lunt PW. A workshop on facioscapulohumeral (LandouzyDéjérine) disease, Manchester, 16 to 17 November 1988. f Med Genet 1989;26:535-7.

6 Sarfarazi M, Upadhyaya M, Padberg G, et al. An exclusion map for facioscapulohumeral (Landouzy-Déjérine) disease. $₹ \mathrm{Med}$ Genet 1989;26:481-4.

7 Upadhyaya M, Sarfarazi M, Lunt PW, Broadhead W, Harper PS. A genetic linkage study of facioscapulohumeral (Landouzy-Dejérine) disease with 24 polymorphic DNA probes. $\mathcal{F}$ Med Genet 1989;26:490-3.

8 Siddique T, Roper H, Pericak-Vance $M$, et al. Linkage analysis in the spinal muscular atrophy type of facioscapulohumeral disease. $\mathcal{F}$ Med Genet 1989;26:487-9.

9 Wijmenga C, Frants RR, Brouwer OF, Moerer P, Padberg GW. The facioscapulohumeral muscular dystrophy gene maps to chromosome 4. Lancet 1990;ii:651-3.

10 Upadhyaya M, Lunt PW, Sarfarazi M, et al. DNA marker applicable to presymptomatic and prenatal diagnosis of facioscapulohumeral disease. Lancet 1990;ii:1320-1.

11 Boyes JW, Fraser FC, Lawler SD, McKenzie HJ. A pedigree of hereditary progressive muscular dystrophy. Ann Eugen 1950;15:46-51.

12 Fitzsimons RB, Gurwin EE, Bird AC. Retinal vascular abnormalities in facioscapulohumeral muscular dystrophy. Brain 1987;110:631-48.

13 Edwards RHT, Griffiths RD, Hayward M, et al. Modern methods of diagnosis of muscle diseases. $\mathcal{F} R$ Coll Physicians Lond 1986;20:49-55.

14 Lunt PW, Compston DAS, Harper PS. Estimation of age dependent penetrance in facioscapulohumeral muscular dystrophy by minimising ascertainment bias. $f$ Med Genet 1989;26:755-60.

15 Weber JL, May PE. Dinucleotide repeat polymorphism at D4S171 locus. Nucleic Acids Res 1990;18:2202.

16 Milner ECB, Lotshaw CL, Willems van DK. Isolation and mapping of a polyanalytic DNA sequence $\mathrm{pH} 30$ on chromosome 4. Nucleic Acids Res 1989;17:4002.

17 Feinberg AP, Vogelstein B. A technique for radiolabelling DNA restriction endonuclease fragments to high specific activities. Anal Biochem 1983;132:6-13.

18 Lathrop GM, Lalouel JM, Julier C, Ott J. Easy calculation of lod scores and genetic risk on small computers. Am $\mathcal{F}$ Hum Genet 1984;36:460-5.

19 Conneally PM, Gusella JF, Wexler NS. Huntington's disease: linkage with $G 8$ on chromosome 4 and its consequences. In: Berg K, ed. Genetic disorders. Medical genetics: past, present, future. New York: Alan R Liss, 1985:53-60. 
20 Lunt PW, Noades JG, Upadhyaya M, Sarfarazi M, Harper PS Evidence against location of the gene for facioscapulohumeral muscular dystrophy on the distal long arm of chromosome 14 f Neurol Sci 1989;88:287-92.

21 Padberg G, Eriksson AW, Volkers WS, et al. Linkage studies in autosomal dominant facioscapulohumeral muscular dystrophy. I Neurol Sci 1984;65:261-8.

22 Padberg GW, Klasen EC, Volkers WS, deLange GG, Wintzen AR. Linkage studies in facioscapulohumeral muscular dystrophy. Muscle Nerve 1988;11:833-5.

23 Lucotte G, Berriche S, Fardeau M. Linkage analysis of French families with facioscapulohumeral muscular dystrophy. $\mathcal{f}$ Med Genet 1989;26:485-6.

24 Love DR, Hill D, Dickson G, et al. An autosomal high molecular weight transcript in skeletal muscle with homology to dystrophin. Nature 1989;339:55-8.
25 Voit T, Lamprecht A, Lenard HG, Goebel HH. Hearing loss in FSHD. Eur $₹$ Pediatr 1986;145:280-5.

26 Buetow KH, Shiang R, Yang Ping, et al. A detailed multipoint map of human chromosome 4 provides evidence for linkage heterogeneity and position specific recombination rates. Am 7 Hum Genet (in press).

27 Kato A, Asakai R, Davie EW, Aoki N. Factor XI gene (F11) is located on the distal end of the long arm of human chromosome 4. Cytogenet Cell Genet 1989;52:77-8.

28 Bodrug SE, Robson JR, Weiss L, Ray PN, Worton RG Van Dyke DL. Prenatal identification of a girl with a $t(X ; 4)(p 21 ; q 35)$ translocation: molecular characterisation, paternal origin, and association with muscular dystrophy. f Med Genet 1990;27:426-32. 